\title{
Plantas geneticamente modificadas com toxinas de Bacillus thuringiensis: uma ferramenta para conferir resistência contra insetos praga*
}

\section{Genetically modified plants expressing Bacillus thuringiensis toxin: A tool to confer resistance against crop insect pests}

Leidiane Eulália Chaves da Costa ${ }^{1}$

Érica Soares Martins Queiroz ${ }^{2}$
* Recebido em: 10/03/2014 Aprovado em: 23/03/2015

1 Graduanda, Faculdade Icesp Promove de Brasília, email: leidianecosta1990@gmail.com;

2 Professora, Faculdades Icesp Promove de Brasília,email: es.martins2@gmail.com.

\section{Resumo}

O uso constante de agroquímicos em lavouras garante o desenvolvimento das plantas livre do ataque de pragas, porém os efeitos maléficos ambientais constitui motivo para se buscar novos métodos que possam suprir a demanda. Estudos que visam ao desenvolvimento sustentável, especificadamente na área de engenharia genética de plantas, permitem a seleção e inserção de genes que expressão proteínas capazes de conferir resistência a insetos-praga. $\mathrm{O}$ estudo relatado neste artigo tem por objetivo realizar o levantamento de eventos geneticamente modificados com toxinas de B. thuringiensis liberados para uso comercial no Brasil nos últimos dez anos e avaliar os impactos e riscos desses eventos, bem como construir instrumentos para divulgação e esclarecimento da população sobre o uso dessa tecnologia. Este artigo fundamentou-se na revisão de literatura acerca de cultivares transgênicas, que expressam genes inseticidas liberadas comercialmente no Brasil, levando-se em consideração os últimos 10 anos, até o período atual.

Palavras-chave: Plantas inseticidas. Gene cry. Proteínas cry. Proteínas inseticidas. Bacillus Thuringiensis.

\begin{abstract}
The constant use of pesticides in crops ensures the development of free plant pest attack, but the environmental harmful effects produced by these chemicals are the reason to seek new methods that can meet the demand. Studies aimed at sustainable development, specifically in the area of genetic engineering of plants, allow the selection and insertion of genes expressing proteins that confer resistance to insect pests. This project aims to carry out the survey of genetically modified events with the B. thuringiensis toxins released for commercial use in Brazil in the last ten years and assess the impacts and risks of these events, as well as building tools for dissemination and awareness of the population about the use this technology. This research is based on literature review about the transgenic cultivars, which insecticides gene expression commercially released in Brazil, taking into account the last 10 years, to the current period.
\end{abstract}

Keywords: insecticidal plants. Cry gene. Cry proteins. Insecticidal proteins. Bacillus Thuringiensis. 


\section{Introdução}

A agricultura constitui prática utilizada desde os primórdios dos tempos pelo ser humano, porém o ataque de pragas compromete o desenvolvimento natural das lavouras afetando a distribuição de alimentos por igual na mesa da população brasileira. Certa carência reflete diretamente na economia, pois ocorre alta no preço dos alimentos e desigualdade social. Visando diminuir essa devastação pelas pragas e os reflexos negativos no meio socioeconômico, surge a era da "Revolução Verde", caracterizada pela implantação do uso de agrotóxicos e fertilizantes, sistema adotado por vários países (BALSAN, 2006).

Inseticidas, fungicidas, herbicidas, nematicidas, acaricidas, rodenticidas, moluscidas, formicidas, reguladores e inibidores de crescimento, são fórmulas ativas para a venda no Brasil, tais venenos são utilizados com a finalidade de preservar a plantação do ataque de pragas existentes na natureza que comprometem o desenvolvimento da planta cultivada (LONDRES, 2011).

Esses insumos proporcionaram o controle de pragas reduzindo os riscos de danos econômicos a diversos países por meio do aumento dos índices da produção agrícola, dessa forma, promovendo o desenvolvimento da agricultura durante anos. Porém, a descoberta dos impactos ambientais em consequência dessa atividade é um efeito progressivo cuja expansão não é tão fácil de ser controlada, uma vez que a morte de insetos-praga acaba causando uma instabilidade na cadeia-alimentar, abrindo nichos que permitem que outros insetos e plantas passem a se comportar como pragas, sendo assim, as indústrias químicas procuram meios de lançar inovações no mercado a fim de manter a estabilidade econômica dos agricultores (PERES, 2001).

No entanto, essa atividade progressiva aumenta os riscos de poluição do ar, do solo e causa danos ao homem e animais mediante a intoxicação alimentar, pois deve-se levar em consideração que muitas das substâncias químicas, agrotóxicos, ao longo dos anos, são capazes de interagir com as moléculas de genes de organismos vivos, levando à seleção de organismos resistentes e ao aumento de incidências de doenças como o câncer (LONDRES, 2011).

O avanço nos estudos científicos e tecnológicos ao longo dos anos tem contribuído para o desenvolvimento de meios alternativos na produção agrícola, tais como o uso de métodos ligados à Biologia Molecular e a aplicação da Engenharia Genética na produção de Organismos Geneticamente Modificados (OGM's).

O DNA é transcrito em RNA que traduzido em proteínas expressará as características fenotípicas das plantas. Tem-se as folhas, o caule, a flor e o fruto como exemplo dessas características, dependendo da planta, os valores nutricionais ficarão concentrados em uma determinada região específica. No ciclo natural de alguns vegetais, os valores nutricionais relevantes à alimentação humana não se expressam com tanta intensidade como deveria.

Nesse contexto, as aplicações da engenharia genética, por meio do melhoramento genético em plantas, são fundamentais não apenas para derivar outras linhagens de cultivares que detenham das mesmas características fenotípicas originais e valores nutricionais de potencial mais elevado, mas também pode garantir que a planta seja resistente ao ataque de insetos mediante técnicas de inserção de genes pré-selecionados de bactérias que detêm efeito tóxico ao ataque de insetos alvos (XAVIER; LOPES; PETERS, 2009).

Para a modernização da agricultura, essa implantação das técnicas de modificação genética é o meio alternativo mais viável para substituir os problemas surgidos pelos efeitos agressivos causados por agrotóxicos nas grandes lavouras. No caso de plantas inseticidas, ocorre a recombinação do DNA entre dois organismos, ou seja, são inseridos genes de uma bactéria denominada Bacillus thuringiensis na sequência de DNA de plantas, dessa forma a planta modificada expressa no seu fenótipo proteínas com finalidade inseticida capazes de matar pragas que venham a se alimentar dessas plantas (MARTINELLI, 2005).

\subsection{Bacillus thurigiensis}

A bactéria Bacillus thuringiensis é um microrganismo de solo, aeróbico, Gram positiva de formato cilíndrico, suas propriedades inseticidas são descritas desde 1091 quando a morte em massa de uma infestação de bichos-da-seda no Japão foi atribuída a uma infecção bacteriana por $B$. thuringiensis servindo como objetivo de estudos para produção de um novo tipo de inseticida (PIONNER, 2008).

A característica inseticida é em virtude de uma proteína denominada Cry (formato de cristal) ou delta toxina produzida durante a fase de esporulação da bac- 
téria B. thuringiensis. A proteína Cry é ativada somente em meio alcalino, pois não possui resistência em meio ácido sendo ligeiramente degrada, deste modo, o risco toxicológico em humanos e animais é praticamente zero, a reação destrutiva ocorre somente a insetos específicos que façam ingestão da planta geneticamente modificada. A atividade entomopatogenica do transgênico bt abrange não só as ordens de insetos lepdoptera, coleóptera e díptera, mas também de alguns invertebrados nematoides, sarcomastigofora e platelmintos. (BAZONI, 2006, BOBROWSKI et al., 2003, BERLITZ; FIUZA, 2005).

As proteínas Cry, após solubilização, sofrem clivagem proteolítica no intestino médio dos insetos, ativando a toxina que é liberada no organismo, o domínio responsável pelo reconhecimento se liga de maneira irreversível ao receptor específico na parede do intestino-alvo. Uma vez ligada, a proteína, provoca paralisia da musculatura intestinal do inseto, inibindo a absorção de alimentos e a formação de poros nas membranas do intestino, levando a um desequilíbrio osmótico que acarreta a morte do inseto. É, por essa razão, que inúmeras proteínas têm especificidades próprias devido à diversidade desses receptores nas diferentes espécies, ordens e classes de insetos. (PIONNER, 2008, FIUZA; PINTO, 2009).

Existem inúmeros genes cry. Até 1998, a denominação abrangia apenas cinco genes principais: cryI, cryII, cryIII, cryiv e crytl. Atualmente, devido à quantidade de genes que são estudados e sequenciados, usam-se números arábicos: cry1, cry2, cry3, cry4... até cry 70 . Os genes cry1, cry2 e cry9 são específicos em relação aos lepidópteros, cry5 são ativos contra nematoides e, cry2, cry $4 A$, cry10, cry11, cry 17, cry 19, cry 24, cry 25, cry 27, cry 29 , cry30, cry32, cry39 e cry40 são ativos contra dípteros. Devido ao grande número de coleções de Bt no mundo, a atualização dos genes Bt é realizada por meio de consulta ao website http://www.lifesci.sussex.ac.uk/home/ neil_Crickmore/Bt// (CARNEIRO, 2009).

A bactéria Bacillus thuringiensis produz outras proteínas chamada Proteínas inseticidas vegetativas (VIPS), assim como a proteína também tem efeito inseticida contra lepidópteros, porém estas são produzidas e secretadas como proteína solúvel na fase de crescimento vegetativo da bactéria, sendo uma importante alternativa para resistência das proteínas cry (PINTO, 2009).

Segundo Secchi (2002), os bioinseticidas, por serem mais seletivos, mais seguros ao aplicador e por não poluírem o meio ambiente, como os agrotóxicos, são uma alternativa verdadeiramente sustentável, que contribui para manter o equilíbrio biológico. Dentre os diversos micro-organismos utilizados em engenharia genética, os genes Bt é o inseticida microbiano mais bem-sucedido e são os que detêm maior aplicação devido ao seu potencial de ação, especificidade e rapidez de biodegradação na proteção de grãos, florestas e no combate a vetores de doenças aos humanos (CAPALBO et. al., 2005)

No Brasil a liberação de plantas transgênicas ocorre mediante a aprovação da Comissão Técnica Nacional de Biossegurança (CTNBio), esse órgão é responsável em fiscalizar desde a transformação ao desenvolvimento do OGM, sendo assim as empresas são responsáveis por comprovar a igualdade dos caracteres da planta modificada com a planta convencional (folhas, sementes, flor, frutos), a forma de desenvolvimento e crescimento normal, se oferece riscos à saúde humana, ambiental e animal, apresentando resultados positivos, é deferido a liberação comercial. O pedido das empresas requisitantes é feito conforme Instrução Normativa CTNBio no 3, de 12.11.96 (COMISSÃO TÉCNICA NACIONAL DE BIOSSEGURANÇA, 1996).

Dentre as liberações comerciais de transgênicos, destacam-se produtos como o milho, algodão e soja. Das plantas modificadas e liberadas comercialmente no Brasil e no mundo, têm-se os transgênicos: Algodão Bolgard I Roundup Ready (MON531\&MON1445), Algodão Bolgard I (MON531), Algodão Bolgard 11 Roundup Ready Flex (MON 15985 X MON 88913), Algodão GlytolxTwinLink (GHB614 X T304-40 X GHB 119), Algodão TwinLink (T304-40 x GHB119), Algodão Widestrike (281-24-236 \& 3006-210-23), Algodão Bolgard II (MON15985), milho MON POWER Core PW/Dow $($ MON89034 × TC1507 × NK603), Milho HX YG RR2 (TC1507 x MON810 x NK603), Milho MON89034 X MON88017, Milho Yield Gard (MON810), Milho TL (bt11), Milho Herculex (TC1507), Milho YR YieldGard/ RR2 (NK603 \& MON810), Milho TL/TG (Bt11 \& GA21), Milho Viptera- MIR 162 (MIR162), Milho HR Herculex/ RR2 (TC1507 \& NK603), Milho TL TG VIPTERA (Bt11 \& MIR162 \& GA21), Milho Yield Gard VT (MON88017), Milho (TC1507XMON810) e a Soja MON 87701 x MON 89788 (BRASIL, 2012).

O objetivo dessa revisão foi apresentar o levantamento de eventos (cultivares) geneticamente modificados com toxinas de B. thuringiensis liberados para uso comercial no Brasil nos últimos dez anos. 


\section{Metodologia}

O estudo foi realizado por meio de revisão de literatura acerca de cultivares transgênicas que expressem genes inseticidas liberadas comercialmente no Brasil, levando-se em consideração os últimos 10 anos até o período atual. Foram consultados livros, periódicos, monografias e dissertações de mestrado de teses de doutorado. A busca de artigos científicos foi realizada por meio dos bancos de dados da CTNBio, Bireme e Scielo, PubMed e, Medline. Foram utilizadas palavras-chave tais como: plantas inseticidas, gene cry, proteínas Cry, proteínas inseticidas e Bacillus thuringiensis.

A partir do levantamento, os dados foram quantificados e tabulados a fim de se obter um perfil de cultivares no Brasil, apresentando ainda os riscos e os benefícios do cultivo e utilização de plantas que expressem genes inseticidas.

\section{Resultados}

Embora a engenharia genética de plantas tenha aplicação benéfica no uso comercial a fim de conferir resistência a insetos-praga, isso não exclui a possibilidade de causar danos à saúde humana, animal e ao meio ambiente, é visando a esses riscos ao ecossistema que são realizados inúmeros testes para se obter resultado preciso setos pragas, melhorar a qualidade da planta e tornar o cultivo um processo econômico ao agricultor.

Nesse contexto, a solicitação de liberação comercial ocorre por meio de parecer das empresas responsáveis pela construção das OGM's, apresentando os testes realizados e os resultados de produtos transgênicos como a Soja MON 87701 x MON 89788; o Algodão TwinLink (T304-40 x GHB119) e o Milho TC1507 x MON810 x NK603, sendo favoráveis os resultados, é deferido o pedido do requerente pela CTNBio para o uso comercial.

Com base nos documentos analisados constatou-se que no Brasil e no mundo, o milho com $66 \%$ dos dados apurados detém uma predominância maior entre os transgênicos liberados comercialmente quando comparado ao algodão e a soja, sendo que o algodão detém $30 \%$ do uso comercial e a soja $4 \%$ conforme ilustrado na figura 1.

Praticamente todos os países produzem milho. Ao todo, são 160 milhões de hectares e 800 milhões de toneladas atuais. No Brasil, terceiro maior produtor mundial, atrás dos Estados Unidos e da China, são produzidos em média 30 milhões de toneladas de grãos de milho por ano, esse avanço na produção se caracteriza pelas suas propriedades que são utilizadas diretamente para consumo humano e animal, assim como, no ramo industrial na produção de bebidas, medicamentos, plásticos etc. (ABRAMILHO, 2010).

Figura 1 - Variedades de plantas transformadas com genes cry liberadas no Brasil

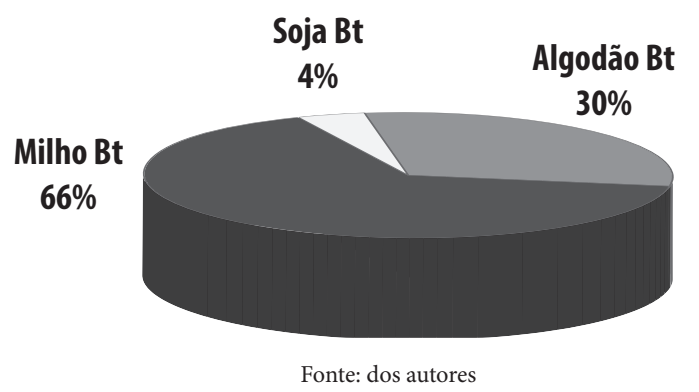

A proteína Cry extraída da bactéria $B$. thuringiensis não compromete a alimentação humana e animal, tendo em vista que, para manifestar seus efeitos de toxidade, é necessário ter contato com o meio básico, tal como o organismo de insetos, desse modo a possibilidade de causar efeitos alergênicos ao organismo humano e animal atinge um risco quase zero. Em aplicações ambientais, a planta é igual à de referência, quando não, as diferenças são mí- 
nimas a tal ponto de não comprometer a integridade do solo, do cultivo, do crescimento e do desenvolvimento da planta (PINTO; FIUZA, 2008).

Os genes $\operatorname{cry} 1 \mathrm{Ab}(25 \%)$ e crylF(16\%) representados na figura 2, são os mais usados na construção de cultivares transgênicos, isso porque esses são os genes mais estudados conferindo resultados efetivos no controle a lepidópteros, testes comprovam que essas proteínas foram facilmente degradas no meio gástrico e não têm homologia de sequência com alérgenos e toxicidade conhecidas, o que implica que não representam interferente ao alimento humano e animal. Segundo estudo realizado por Guidelli-Thuler et al. (2008), esses genes foram predominantes em isolados de $B$. thuriginesis.

Figura 2 - Frequência de genes expressos em plantas contendo genes inseticidas e não inseticidas de acordo com os documentos analisados.

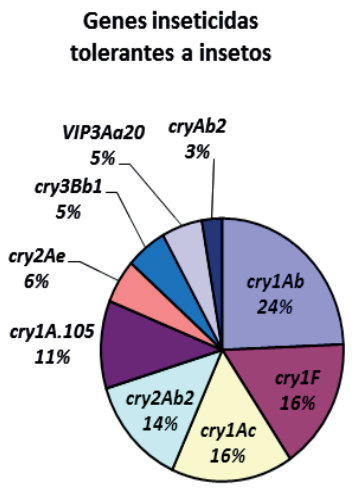

\section{Genes não inseticidas} tolerantes a herbicidas

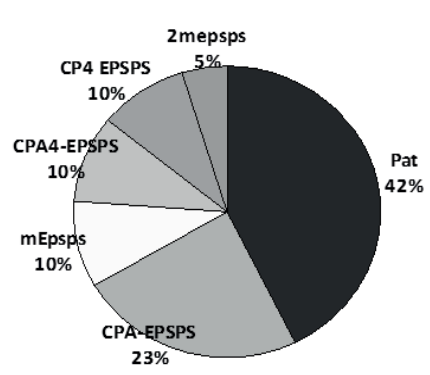

Fonte: dos autores

Os organismos não alvo terrestres e de solo testados não foram atingidos pela proteína Cry1 $\mathrm{Ab}$, mesmo com níveis superiores aos máximos que poderiam ser verificados em caso de exposição natural. Adicionalmente, comparações entre as proteínas Cry produzidas por $B$. thuringiensis e a proteína Cry1 $\mathrm{Ab}$ produzida pelo milho MON810 demonstrou que elas podem persistir em solos tropicais por mais tempo devido à sua ligação às partículas de argila (SANDERS et al., 1998).

O gene pat (42\%), representado na figura 2, derivado de Streptomyces viridochromogenes, confere resistência a herbicidas glifosato, comumente utilizado para o controle de plantas daninhas. Esse gene é o mais utilizado em combinações com os genes de B. thuringiensis em plantas como o milho, algodão e a soja para obter uma planta com o máximo de proteção contra os seus interferentes naturais de desenvolvimento, em seguida tem-se o gene CPA-EPSPS (23\%) derivados de cepas de Agrobacte- rium tumefaciens.

O Conselho de Informações sobre Biotecnologia revela os países que obtiveram liberação comercial para o cultivo de soja, milho e algodão Bt. Dentre esses destacam-se Brasil, Estados Unidos, Japão, México, Austrália, Coreia do Sul, Filipinas, Canadá, Colômbia, Nova Zelândia, África do Sul, Argentina, China, União Europeia, Taiwan, Uruguai, Honduras, Russia, Indonesia, Paraguai, Malasia, Turquia, Burquina Faso, Egito, India e Singapura, conforme ilustrado na figura 3 .

Figura 3 - Plantas Bt liberadas comercialmente no Brasil e no mundo, compiladas de acordo com os documentos analisados.

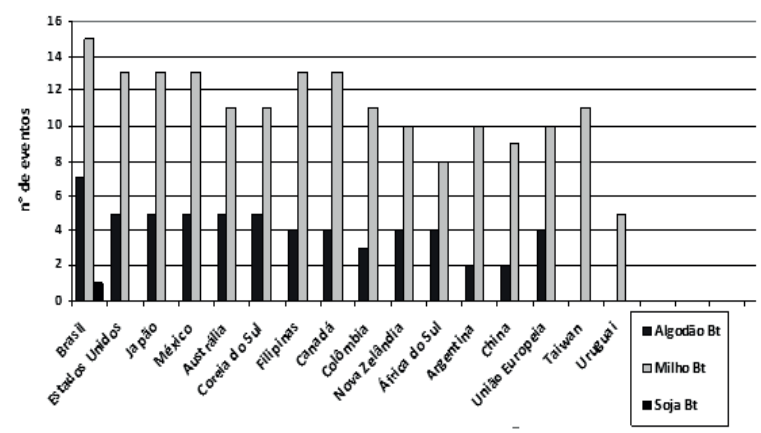

Fonte: dos autores

O Brasil é o terceiro maior produtor mundial de milho com uma produção de aproximadamente $35 \mathrm{mi}$ lhões de toneladas no ano de 2005, atrás somente dos Estados Unidos da América (282 milhões de toneladas) e da China (139 milhões de toneladas) (DUARTE, 2011).

Segundo dados econômicos da Companhia $\mathrm{Na}$ cional de Abastecimento (CONAB) sobre as safras de 2011/2012 o maior produtor de soja convencional no mundo são os Estados Unidos, seguido do Brasil que ocupa o segundo lugar na escala de produção (COMPANHIA NACIONAL DE ABASTECIMENTO, 2013).

A soja é uma espécie exótica no Brasil e não existem parentes silvestres capazes de cruzar e originar descendentes. Por esse fato, o Brasil é o único que detém a liberação comercial de soja transgênica em relação aos outros países do mundo. O fluxo gênico entre plantas de soja já foi estudado em condições tropicais. A soja é uma espécie autógama com flores completas, sendo descritas taxas muito baixas de polinização cruzada, isso conforme tipo de cultivar e localidade (COMISSÃO TÉCNICA NACIONAL DE BIOSSEGURANÇA, 2010).

As pragas, nos últimos anos, têm-se tornado uns dos principais limitantes na cultura de algodão, milho e soja no Brasil, principalmente os insetos da ordem Lepi- 
doptera (lagarta curuquerê; lagarta da espiga (Helicoverpa zea); lagarta da maçã (Heliothis virescens); lagarta militar; lagarta rosada (Pectinophora gossypiella); falsa medideira (Pseudoplusia includens); lagarta do cartucho (Spodoptera frugiperda), lagarta do colmo, broca da cana, lagarta rosca, lagarta da soja), como compilado e apresentado na figura 4.

Figura 4 - Insetos atingidos pelas espécies transformadas de algodão, milho e soja no Brasil.

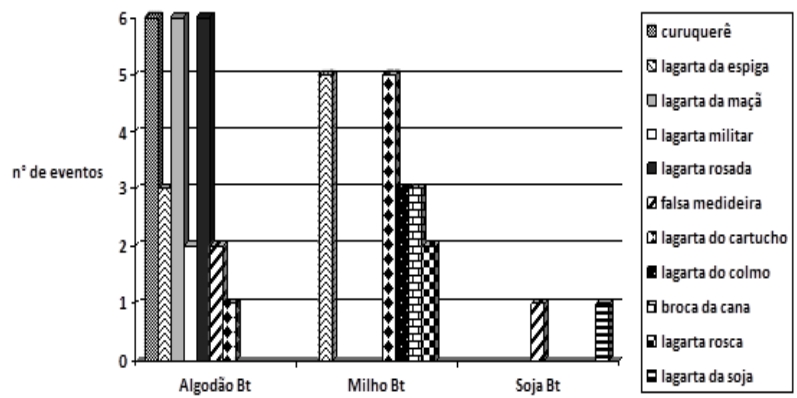

Fonte: dos autores

A estimativa de perdas no plantio de grãos de milho podem alcançar cerca de $34 \%$ na escala de produção, isso devido ao ataque de insetos-pragas, dentre as quais destacam-se os lepdópteros como a lagarta do cartucho Spodoptera frugiperda e a broca da cana Diatraea saccharalis. Alimentam-se em todas as fases de crescimento da cultura. Com base nesses dados, a aplicação da técnica de manejo utilizando a tecnologia $\mathrm{Bt}$, trouxe uma alternativa rentável a fim de reduzir as interferências das pragas nesse processo de desenvolvimento do cultivar. Muitos agricultores adotaram a biotecnologia, a expectativa é que cerca de 50\% da área plantada seja de milho Bt. (CRUZ, 1995, FIGUEIREDO et al., 2006, MENDES; WAQUIL, 2009)

Segundo dados do Ministério da Agricultura, Pecuária e Abastecimento (MAPA) concomitante aos dados estatísticos da Associação Brasileira dos Produtores de Algodão (ABRAPA), o Brasil passou de maior importador mundial de algodão para o terceiro maior exportador. No cenário interno, o cultivo do algodão também é favorável, pois o país é o quinto maior consumidor com quase 1 milhão de toneladas por ano. A garantia de produção de algodão começa principalmente no controle de pragas no cultivo dos algodoeiros (ASSOCIAÇÃO BRASILEIRA DOS PRODUTORES DE ALGODÃO, 2014).

Dentre as as principais pragas que atacam os algodoeiros no Brasil, destacam-se: a lagarta curuquerê (Alabama argillacea), a lagarta-da-maçã (Heliothis vi- rescens) e a lagarta-rosada (Pectinophora gossypiella). O controle dessas pragas tem sido realizado principalmente com o uso de inseticidas, a utilização excessiva dessas substâncias químicas não específicas leva a impactos ambientais negativos, como a redução severa da população de organismos benéficos e a potencialização do surgimento de pragas resistentes aos inseticidas convencionais (RICHETTI, 2003, TORRES, 2005)

Dessa forma, a eficiência da expressão de proteínas oriundas de $B$. thurigiensis mostra-se eficaz no controle dessas pragas sem provocar efeitos ambientais severos, garantindo que a planta se desenvolva sem causar efeitos positivos ou negativos em populações não alvo, o que reflete diretamente na área econômica de comercialização interna e externa pelos agricultores no mundo todo (SUJII et al., 2008).

$\mathrm{O}$ algodão é mais vulnerável ao ataque de lepidopteros em relação ao milho e à soja, embora haja mais liberações comerciais de milho Bt no Brasil. Os baixos índices de ataque ao cultivo de soja (Figura 4) podem ser observados porque há apenas uma liberação desse cultivar no mundo.

\section{Conclusão}

As conquistas atuais no controle de pragas com as aplicações de engenharia genética são resultados de estudos prolongados. Os bioinseticidas formulados à base de B. thuringiensis vêm apresentando resultado satisfatório no controle de lepidópteros, desse modo se torna uma alternativa sustentável, apresentando riscos ambientais significativamente menores quando comparados aos inseticidas químicos.

O mecanismo de ação das proteínas Cry só é possível mediante a ligação nos receptores específicos de insetos alvos, esse fato comprova que os riscos de atingir insetos não alvos é quase zero, assim como as chances de causar alguma patogenicidade em organismos de humanos é também considerada baixa, uma vez que, para manifestar os seus efeitos tóxicos o meio deve ser alcalino, caso contrário, a proteína é facilmente degrada. Em relação ao meio ambiente, não há indícios que comprovem que as plantas $\mathrm{Bt}$ comprometem o desenvolvimento de outras plantas, a similaridade com a planta original se enquadra em todos os aspectos, a começar pela semente até as folhas, flores e frutos.

Esses resultados mostram os avanços das pesqui- 
sas e a eficácia da forma de ação das plantas Bt, pois o custo-benefício é relativamente melhor tendo por base o aproveitamento das lavouras por meio da prevenção do ataque de insetos, a redução de substâncias químicas liberados no meio ambiente e a conservação dos nutrientes naturais da planta sem a interferência de agrotóxicos.

Em consequência, a disponibilização dos produtos transgênicos à população brasileira revela que o nosso país tem a mesma capacidade de produção dos países de primeiro mundo. Com isso, o Brasil passa a ser visto não só como um país em desenvolvimento econômico, mas também em avanço da Biotecnologia.

\section{Referências}

ABRAMILHO. A dimensão do milho no mundo. Disponível em: <http://www.abramilho.org.br/noticias. php?cod=975>. Acesso em: 10 dez. 2014.

ASSOCIAÇÃO BRASILEIRA DOS PRODUTORES DE ALGODÃO. O algodão no Brasil: estatísticas. Disponível em: <http://www.abrapa.com.br/estatisticas/Paginas/ Algodao-no-Brasil.aspx>. Acesso em: 10 dez. 2014.

BALSAN, R. Impactos decorrentes da modernização da agricultura brasileira. Campo Território: Revista de Geografia Agrária, Uberlândia, v. 1, n. 2, p. 123-151, ago. 2006.

BAZONI, M. O. Clonagem, caracterização do gene $v i$ p3A de Bacillus thuringiensis e transformação de Agrobacterium tumefaciens. 2006. 50 f. Dissertação (Mestrado) - Programa de Pós-Graduação em Agronomia, Universidade Estadual Paulista, Jaboticabal, 2006.

BERLITZ, D. L.; FIUZA, L. M. Bacillus Thurigiensis e Melia Azedarach: aplicações e interações no controle de insetos-pragas. Biotecnologia: Ciência e Desenvolvimento, Brasília, v. 35, p. 66-72, jul./dez. 2005.

BOBROWSKI, V. L. et al. Genes de Bacillus Thuringiensis: uma estratégia para conferir resistência a insetos em plantas. Ciência Rural, Santa Maria, v. 33, n. 5, p. 1-9, set./out. 2003.

CAPALBO, D. M. F. et al. Bacillus thurigiensis: formulações e plantas transgênicas. Biotecnologia Ciência e Desenvolvimento, Brasília, v. 34, p. 78-85, jan./jun. 2005.

CARNEIRO, A. A. et al. Milho Bt: teoria e pratica da produção de plantas transgênicas resistentes a insetos-praga. Sete Lagoas: Embrapa Milho e Sorgo, dez. 2009. (EMBRAPA-CNPMS. Circular técnica, 135)
COMPANHIA NACIONAL DE ABASTECIMENTO. Acompanhamento da safra brasileira de grãos: Safra 2013/14, decimo segundo levantamento Brasília: Conab, 2013. v. 1.

COSTA, M. A. F.; COSTA, M. F. B. Biossegurança de OGM: uma visão integrada. Rio de Janeiro: FIOCRUZ, 2009.

CRUZ, I. A Lagarta-do-cartucho na cultura do milho. Sete Lagoas: Embrapa Milho e Sorgo, 1995. (EMBRAPA-CNPMS. Circular técnica, 21).

COMISSÃO TÉCNICA NACIONAL DE BIOSSEGURANÇA. Instrução Normativa n. 3, de 12 de novembro de 1996. Normas para liberação planejada no meio ambiente de Organismos Geneticamente Modificados. Disponível em: <http://www.ctnbio.gov.br/index.php/ content/view/139.html>. Acesso em: 12 maio 2014.

COMISSÃO TÉCNICA NACIONAL DE BIOSSEGURANÇA. Parecer técnico N. 2542, 20 de agosto de 2010. Liberação comercial de soja geneticamente modificada resistente a insetos e tolerante a herbicida. Requerente: Mondanto do Brasil Ltda Disponível em: <http://www.ctnbio.gov.br/index.php/content/view/15347.html>. Acesso em: 12 nov. 2014

DUARTE, J. O.; GARCIA, J. C.; MIRANDA, R. A. Cultivo do Milho. 7 ed. Sete Lagoas: Embrapa Milho e Sorgo, set. 2011. (Sistema de Produção, 1).

FIGUEIREDO, M. L. C.; MARTINS-DIAS, A. M. P.; CRUZ, I. Relação entre a lagarta-do-cartucho e seus agentes de controle biologico natural na produção de milho. Pesquisa Agropecuária Brasileira, Brasilia, v. 41, n. 12, p. 1693-1698, dez. 2006.

FIUZA, L. M.; PINTO, L. M. N. Plantas transgênicas que sintetizam toxinas de Bacillus Thuringiensis e outras. Biotecnologia Ciência e Desenvolvimento, Brasília, v. 38, p. 62-67, jan./dez. 2009.

GUIDELLI-THULER, A. M. G. et al. Bacillus thurigiensis: diversidade gênica em isolados lepidoptera-específicos. Arquivos do Instituto Biológico, São Paulo, v. 75, n. 4, p. 409 , out./dez., 2008

LONDRES, F. Agrotóxicos no Brasil: um guia para ação em defesa da vida. Rio de Janeiro: AS-PTA, 2011.

BRASIL. Ministério da Agricultura, Pecuária e Abastecimento. Listagem de OGM's Autorizados no Brasil. 2012. Disponível em: <file://D:/LISTAGEM\%20DE\%20 OGM\%20AUTORIZADOS\%20NO\%20BRASIL.pdf>. Acesso em: 10 dez. 2014. 
MARTINELLI, S.; OMOTO, C. Resistência de insetos a plantas geneticamente modificadas: relevância da implantação de estratégias pró-ativas para o manejo da resistência. Biotecnologia Ciência e Desenvolvimento, Brasília, v. 34, p. 67-77, jan./jun. 2005.

MENDES, S. M.; WAQUIL, J. M. Uso do milho Bt no manejo integrado de lepidópteros-praga: recomendações de uso. Sete Lagoas: Embrapa Milho e Sorgo, 2009. (Comunicado técnico, 170).

PERES, J. R. R. Transgênicos: os benefícios para um agronegócio sustentável. Cadernos de Ciência e Tecnologia, Brasília, v. 18, n. 1, p. 13-26, jan./abr. 2001.

PINTO, L. M. N. et al. Toxinas de Bacillus thuringiensis. Biotecnologia Ciência e Desenvolvimento, Brasília, v. 38, p. 24-31, jan./dez. 2009.

PINTO, L. M. N.; FIUZA, L. M. Genes cry de Bacillus Thuringiensis aplicados na engenharia genética de plantas, conferindo resistência a insetos-praga. Neotropical Biology and Conservation, São Leopoldo, v. 3, n. 3, p. 159-168, set./dez. 2008.

PIONEER. Milho Pioneer com gene YeldGard. Pioneer Responde, Santa Cruz do Sul, v. 5, p. 3-15, ago. 2008. Disponível em: <http://www.pioneersementes.com.br/ DownloadCenter/Revista-Pioneer-Responde-N5-Milho-Bt.pdf $>$. Acesso em: 11 dez. 2014.
RICHETTI, A et al. Cultura do algodão no Cerrado. Campina Grande: Embrapa Algodão. jan. 2003. (Sistemas de Produção, 2)

SANDERS, P. R. et al. Safety assessment of insect-protected corn. In: THOMAS, J. A. Biotechnology and safety assessment. 2 ed. Philadelphia: Taylor and Francis, 1998. p. 241-256.

SCHOLZE, S. H. C. Biossegurança e alimentos transgênicos: o papel da CTNBio. Biotecnologia Ciencia e Desenvolvimento, Brasília, v. 9, p. 32-34, jul./ago. 1999.

SECCHI, V. A. Baculovírus, mais do que uma grande descoberta: uma revolucionária alternativa aos agrotóxicos. Agroecologia e Desenvolvimento Rural Sustentável, Porto Alegre, v. 3, n. 3, p. 49-54, jul. 2002.

SUJII, E. R. et al. Impacto do algodoeiro Bt na dinâmica populacional do pulgão-do-algodoeiro em casa de vegetação. Pesquisa Agropecuária Brasileira, Brasília, v. 43, n. 10, p. 1251-1256, out. 2008.

TORRES, J. B. Controle de pragas do algodoeiro: expectativas de mudanças. Ciência Agrícola, Maceió, v. 8, n. 1, p.37, jan./dez. 2005/2006.

XAVIER, E. G.; LOPES, D. C. N.; PETERS, M. D. P. Organismos geneticamente modificados. Archivos de Zootecnia, Córdoba, v. 58, n. 1, p. 15-33, mar. 2009. 